\title{
Editorial-the 7th International Workshop on Modeling the Ocean (IWMO 2015)
}

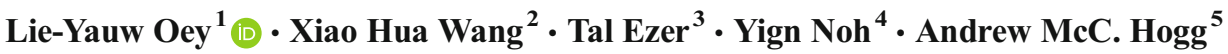

Received: 12 September 2017 / Accepted: 14 September 2017 /Published online: 14 October 2017

(C) Springer-Verlag GmbH Germany 2017

IWMO 2015 was held in the pristine campus of the Australian National University, Canberra, Australia, from June 1-5, 2015. Despite the negative Coriolis spin that many of us from the northern half of the globe experienced for the first time, we were positively impressed by the vastness and beauty of Australia and the kindness and friendliness of its people. Late fall in Canberra displayed spectacular starry nights and brisk sunny days. The workshop was attended by more than 80 participants from 16 countries around the globe. Seventy papers including both oral and posters were presented, covering a very broad range of topics on observations and models: climate variability, basin circulation and coastal oceanography, air-sea interaction, sea-ice dynamics, sediment transport, tropical cyclones, biogeochemical-physical coupling, boundary currents, sea level rise, extreme events, ocean prediction, and others. As in the past years, many of the participants were

Responsible Editor: Jörg-Olaf Wolff

Lie-Yauw Oey

lyooey@gmail.com

1 Institute of Hydrological \& Oceanic Sciences, National Central University, No.300, Zhongda Rd., Jhongli City, Taoyuan County 320, Taiwan

2 The Sino-Australian Research Centre for Coastal Management, School of Physical, Environmental and Mathematical Sciences, UNSW Canberra, Australian Defence Force Academy, PO Box 7916, Canberra 2610, Australia

3 Department of Ocean, Earth \& Atmospheric Sciences, Old Dominion University, Norfolk, VA, USA

4 Department of Atmospheric Sciences, Yonsei University, 134 Sinchon-dong, Seodaemun-gu, Seoul 120749, South Korea

5 Research School of Earth Sciences, The Australian National University, Canberra 0200, Australia students and young scientists - all presented very high-quality research, and three were selected to receive the Outstanding Young Scientist Awards (OYSA). In order that some of us may have a chance to also receive some recognition for our hard work, new this year were three Best Presentation Prizes (BPP), given to any presenters deemed qualified by the audience to receive the honors. Also, new this year were special lunch-time sessions when young and more senior scientists exchanged ideas on a wide range topics.

The 10 papers in this Topical Collection were selected from a total of 20 originally submitted papers after they underwent the usual process of reviews and revisions. There were at least 2 reviewers for each paper. The reviews were solicited from both the workshop attendees and the scientific community at large.

The subjects of papers in this Topical Collection include one on process study of the gravity current (Berntsen et al. 2016), three on data assimilations (Margvelashvili et al. 2016; Peng et al. 2016; Zheng et al. 2016), two on basin-scale modeling and observational data analyses (Ezer 2016; Quan et al. 2016), two on coastal processes (Liu and Chua 2016; Zhu et al. 2016), and two on sediment resuspension and tranport (Qiao et al. 2016; Yang et al. 2016).

Berntsen et al. (2016) conducted a high-resolution model experiment using a non-hydrostatic model to simulate plume down a canyon under rotation. A laboratory-scale model is set up. One of the goals of the study is to verify the results of the model against the laboratory plume under controlled conditions. Additionally, the model provides very detailed descriptions of the flow field and an increased insight into the plume dynamics. Although the plume head becomes less developed under rotation, fluid parcel moves down the canyon following a helix-like path, which often increases the entrainment. The study provides insights into the physics which may occur as dense water overflows into the ocean's interior, a topic which 
is of immense importance to understanding the global thermohaline circulation.

Margvelashvili et al. (2016) first conducted numerical experiments with a chaotic Lorenz-type model to test various aspects of the method and then demonstrated the utility of the method with a 3D high-resolution data assimilation sediment transport model of the Great Barrier Reef in Australia. The idea behind emulators is to reduce the complexity of models so that they can run much faster, while still maintaining enough accuracy for the processes involved. The emulator learns the behavior of a system from an ensemble of model runs. These emulators can form the basis for efficient data assimilation methods, though such applications in ocean modeling and prediction systems are rare and need further investigations. The results showed that localized treatment of the emulation can improve the accuracy of the data assimilation.

Peng et al. (2016) described and evaluated a threedimensional variational data assimilation (3DVAR) system based on the Regional Ocean Modeling System (ROMS) for the South China Sea. Different combinations of potential data sources and coverages have been evaluated. The experiments showed the advantage of assimilating sea surface height data or surface velocities, since they can influence subsurface fields, compared with assimilation of other data such as sea surface temperature and salinity which have only limited influence beyond the surface mixed layer. Combining surface observations with vertical profile data of temperature and salinity can lead to improved representation of mesoscale eddies in the region.

Zheng et al. (2016) presented an interesting modification of the 4DVAR data assimilation scheme in which the linear tangent equation is approximated by introducing perturbations to the parameters to be estimated and then running the ensemble models as in the ensemble Kalman filter method (Evensen 1994; Xu et al. 2013; Xu and Oey 2014). In this way the adjoint equation is not required. The authors successfully tested the method to storm surge simulation in the North Sea-using the wind drag coefficient as the control parameter.

Ezer (2016) wondered if short-term coastal sea level fluctuations with time scales of days to weeks along the eastern coast of the USA and Canada may be caused by similar fluctuations in the Gulf Stream transport. An idealized Princeton Ocean Model (POM) that incorporates only forcing from the Florida Current, the (Labrador) Slope Current, and the Sargasso Sea flows, but excluding other forcing such as estuarine outflows and winds, is used. Coastal sea level fluctuations are sensitive to variation in all three transports through changes in the seasurface gradient across the Gulf Stream and the radiation of coastal-trapped waves. The resulting fluctuations have amplitudes comparable to those caused by $5 \mathrm{~m} / \mathrm{s}$ winds.
As the planet warms and sea level continues to rise particularly along the North American eastern seaboard, understanding such fluctuations is of great practical value in possibly assessing the predictability of coastal floods and inundations.

Quan et al. (2016) use reanalysis data as well as in situ and remote sensing data to study the western boundary current in South China Sea. Due to the Sea's low latitude and relatively narrow width, the Rossby wave response time is short. The western boundary current varies seasonally, it is driven by wind stress curl as well as inflow from the Luzon Strait (Xu and Oey 2015; Lin et al. 2016), and modulated by rich interannual and interdecadal variability due to, e.g., the El Niño-Southern Oscillation and the Philippines-Taiwan Oscillation (Chang and Oey 2012). Quan et al. (2016) propose that the South China Sea western boundary current (SCSWBC) should be defined as the current that flows southwestward and southward along the northern and western slopes of the SCS, while the flow along the Sea's southwestern shelf is considered as part of the locally wind-driven shelf circulation. The authors show analyses that support this view. As SCS spans a large latitudinal range from $8 \sim 20^{\circ} \mathrm{N}$, the proposed finding is consistent with the fact that the Rossby response time is indeed very much shorter in the southern portion of the basin than in the northern portion (by approximately the square of the ratio of south to north Coriolis parameters).

Liu and Chua (2016) developed a "local exact particle tracking" model. Accurate Lagrangian simulation of trajectories and distribution of particles and tracers are of great interest in oceanographic research and practical marine prediction. Accurate tracking of the mode water, for example, can provide an improved understanding of how subducted greenhouse gases may be distributed in the ocean, and reliable calculation of paths of surface-borne objects can aid in search and rescue and/or pollutant tracking. Using idealized flow fields for which exact trajectories are known, they compared the particle trajectories using the new method with traditional calculations using, e.g., the fourth order Runge-Kutta. The new model is found to provide very accurate result.

Based on residual fluxes, Zhu et al. (2016) developed a new method to compute the tidally averaged transport velocities for water (TA-WTV) and substance (TA-STV), which are important physical quantities over estuarine, coastal, and shelf waters. The main advantage of these newly defined transport velocities is that they can be used to quantify differences in amplitude and direction between the tidally averaged water and substance transports. Numerical results of sea surface elevations, currents, and salinity produced by a triply-nested coastal ocean model for the Pearl River Estuary (PRE) were used to calculate 
the TA-WTV and TA-STV for salt (TA-STVsa). The general features of the TA-WTV and TA-STVsa are similar over the most part of the PRE, but differ significantly in amplitude and direction over the salinity frontal zone.

Based on field observations in 4 different seasons of 2010-2011 and 15 numerical experiments, Qiao et al. (2016) studied the seasonal sediment transportation and deposition in the Bohai Sea (BS) and Yellow Sea (YS) of the western North Pacific. The Yellow River is well known for high concentration of suspended particulate matter (SPM), which is one of the most important SPM sources in the BS and YS. Results show that the horizontal distribution of suspended sediment concentration in the BS and YS is neither closely related to the Yellow River discharge in flood and dry seasons nor to the temperature and salinity distributions in winter and summer. Instead, the winter northerly wind events, especially the winter storm events with high waves, are the major factors inducing the long-distance transport of the sediments from the BS to the YS. Further, the net SPMs are transported to the YS from the BS in both winter and summer.

Yang et al. (2016) described measurements of tides, currents, waves, and sediments at three locations in the Yellow Sea. The study found significant correlations between the suspended sediment concentration and shear stress, allowing the estimation of critical shear stresses for seabed erosion at the three sites which represent different cohesive and noncohesive sediments. The critical shear stresses found at the three sites were lower than those of existing models. These discrepancies were explained by the existence of intermittent turbulence events at these sites and the difference between smallscale lab results of suspended sediment and the largescale environment of shallow coastal areas.

We wish to thank our host, Prof. Xiao Hua Wang, and scientists and staff of UNSW and ANU for their warm hospitality and help during the workshop. LYO wishes to thank Prof. Xiao Hua Wang in particular for his tremendous effort and hard work in preparations for the workshop. We also thank the Chief Editor Prof. Jörg-Olaf Wolff of Ocean Dynamics for help and encouragements throughout the process of preparing this Topical Collection. Last but not least, we thank all the reviewers for their help in ensuring that the submitted manuscripts are held to the highest standard. The workshop was sponsored by CSIRO, Canberra Convention Bureau/Think Canberra, ARC Centre for Excellence/Climate System Science, UNSW Canberra, and the Sino-Australian Research Centre for Coastal Management.

\section{References}

Berntsen J, Darelius E, Avlesen H (2016) Gravity currents down canyons: effects of rotation. Ocean Dyn 66(10):1353-1378. https://doi.org/ 10.1007/s10236-016-0981-8

Chang Y-L, Oey L-Y (2012) The Philippines-Taiwan Oscillation: monsoon-like interannual oscillation of the Subtropical-Tropical Western North Pacific Wind System and its impact on the ocean. J Clim 25:1597-1618

Ezer T (2016) Can the Gulf Stream induce coherent short-term fluctuations in sea level along the US East Coast? A modeling study. Ocean Dyn 66(2):207-220. https://doi.org/10.1007/s10236-016-0928-0

Evensen G (1994) Sequential data assimilation with a nonlinear quasigeostrophic model using Monte Carlo methods to forecast error statistics. J Geophys Res. 5, 10143-10162

Lin YC, Oey L-Y, Wang J, Liu KK (2016) Rossby waves and eddies observed at a temperature mooring in northern South China Sea. J Phys Oceangr. https://doi.org/10.1175/JPO-D-15-0094.1

Liu G, Chua VP (2016) A SUNTANS-based unstructured grid local exact particle tracking model. Ocean Dyn 66(6):811-821. https://doi.org/ 10.1007/s10236-016-0952-0

Margvelashvili NY, Herzfeld M, Rizwi F, Mongin M, Baird ME, Jones E, Schaffelke B, King E, Schroeder T (2016) Emulator-assisted data assimilation in complex models. Ocean Dyn 66(9):1109-1124. https://doi.org/10.1007/s10236-016-0973-8

Peng S, Zeng X, Li Z (2016) A three-dimensional variational data assimilation system for the South China Sea: preliminary results from observing system simulation experiments. Ocean Dyn 66(5):737750. https://doi.org/10.1007/s10236-016-0946-y

Qiao L, Zhong Y, Wang N, Zhao K, Huang L, Wang Z (2016) Seasonal transportation and deposition of the suspended sediments in the Bohai Sea and Yellow Sea and the related mechanisms. Ocean Dyn 66(5):751-766. https://doi.org/10.1007/s10236-016-0950-2

Quan Q, Xue H, Qin H, Zeng X, Peng S (2016) Features and variability of the South China Sea western boundary current from 1992 to 2011. Ocean Dyn 66(6):795-810. https://doi.org/10.1007/s10236-0160951-1

Xu FH, Oey L-Y (2014) State analysis using the local ensemble transform Kalman filter (LETKF) and the three-layer circulation structure of the Luzon Strait and the South China Sea. Ocean Dyn 64:905-923. https://doi.org/10.1007/s10236-014-0720-y

Xu FH, Oey L-Y (2015) Seasonal SSH variability of the Northern South China Sea. J Phys Oceanogr 45:1595-1609. https://doi.org/10.1175/ JPO-D-14-0193.1

Xu FH, Oey L-Y, Miyazawa Y, Hamilton P (2013) Hindcasts and Forecasts of loop current and eddies in the Gulf of Mexico using local ensemble transform Kalman filter and optimum-interpolation assimilation schemes. Ocean Model 69:22-38

Yang Y, Wang YP, Gao S, Wang H, Shi BW, Zhou L, Wang DD, Dai C, Li GC (2016) Sediment resuspension in tidally dominated coastal environments: new insights into the threshold for initial movement. Ocean Dyn 66(3):401-417. https://doi.org/10.1007/s10236-0160930-6

Zheng X, Mayerle R, Xing Q, Fernández Jaramillo JM (2016) Adjoint free four-dimensional variational data assimilation for a storm surge model of the German North Sea. Ocean Dyn 66(8):1037-1050. https://doi.org/10.1007/s10236-016-0962-y

Zhu S, Sheng J, Ji X (2016) Tidally averaged water and salt transport velocities and their distributions in the Pearl River Estuary. Ocean Dyn 66(9):1125-1142. https://doi.org/10.1007/s10236-016-0975-6 